\title{
Clinical Characteristics and Hearing Results of Sudden Sensorineural Hearing Loss in Child
}

\author{
Dong Joo Shin, Eun Kyung Jung, Chung Man Sung, Sung Su Lee, \\ Hyong Ho Cho, and Yong Beom Cho \\ Department of Otolaryngology-Head and Neck Surgery, Chonnam National University Medical School, Gwangju, Korea
}

\author{
소아 돌발성 난청의 임상적 특징과 결과 \\ 신동주 · 정은경 · 성충만 · 이성수 · 조형호 · 조용범 \\ 전남대학교 의과대학 이비인후과학교실
}

\author{
Received July 26, 2015 \\ Revised October 30, 2015 \\ Accepted November 1, 2015 \\ Address for correspondence \\ Yong Beom Cho, $\mathrm{MD}, \mathrm{PhD}$ \\ Department of Otolaryngology- \\ Head and Neck Surgery, \\ Chonnam National University \\ Medical School, \\ 42 Jebong-ro, Dong-gu, \\ Gwangju 61469, Korea \\ Tel +82-62-220-6785 \\ Fax +82-62-228-7743 \\ E-mailsscrol196@naver.com
}

Background and Objectives Sudden sensorineural hearing loss (SSNHL) in children can occur just as can in adults; in fact, it may last throughout the entire life of a child, affecting the individual much more than when it does to an adult. As there are only a few studies that have focused on SSNHL in childhood, we investigated the clinical characteristics and hearing outcomes of pediatric SSNHL.

Subjects and Method A retrospective review of patients from November 2005 to May 2014 was carried out. Thirty nine patients under the age 15 , who were hospitalized due to SSNHL were enrolled. Of these patients, 226 patients over the age of 15 were collected as a comparison group. Age, sex, underlying disease, site of hearing loss and duration from the onset to treatment were analyzed. We evaluated the overall recovery rate as well as the recovery rate according to accompanying diseases.

Results Recovery rates were comparable between the pediatric and the adult group. Overall recovery rate was $60 \%$ in the pediatric group. Unlike for the adult group, dizziness and tinnitus were not a prognostic factor in the pediatric group. Pediatric patients showed similar overall recovery, whether the treatment initiation was under 7 days or more. Recurrence was seen in 3 patients, of which 2 showed complete recovery.

Conclusion The recovery rate for SSNHL was similar for the pediatric and the adult groups. A higher recurrence rate may alert clinicians to be aware of hearing changes after the recovery in pediatric patients.

Korean J Otorhinolaryngol-Head Neck Surg 2016;59(2):104-9

\section{서 론}

돌발성 난청은 명확한 이유 없이 갑작스런 청력감소를 보 이는 이과적 응급질환으로, 50대에서 가장 발병률이 높으며1) 남녀의 차이는 없는 것으로 알려져 있다. 대부분 일측성으로 발생하지만 환자의 4 17\%는 양측성이다. 미국에서는 10만 명 당 5 20명, 한국에서는 10만 명당 10 명 이상의 유병률을 갖 는다. ${ }^{2,3)}$ 그리고 32 65\%에서는 특별한 치료를 하지 않아도 저 절로 회복되는 양상을 보인다.
돌발성 난청 환자는 12 시간에서 3 일 정도 사이에 3 개 이상 의 연속된 주파수에서 $30 \mathrm{~dB}$ 이상의 청력 감소를 겪는 경우 진단이 가능하다. ${ }^{4)}$

돌발성 난청의 동반증상으로 처음에는 이명이나 이충만감 만을 호소하기도 하고 어지럼증이 약 20 60\%에서 동반되지 만, 그 증상이 심하지 않고 보통 수일 내에 소실된다.

돌발성 난청은 대부분 원인을 찾지 못한다. 원인은 다인성 일 가능성이 높으며 주로 바이러스 감염과 혈관장애가 발병기 전으로 생각된다. 일부에서는 청신경 종양이 원인으로 약 $10 \%$ 
정도에서 돌발성 난청의 양상이 나타난다. ${ }^{5)}$ 바이러스 감염 중 유행성이하선염 바이러스, 홍역 바이러스 등 와우병변을 유 발할 수 있는 바이러스의 혈청변환 빈도가 돌발성 난청 환자 에서 일반인에 비해 높아 돌발성 난청의 원인 중 하나로 생 각된다. ${ }^{6,7)}$

현재까지 알려진 성인 돌발성 난청의 예후에 미치는 인자 는 청력저하 발생 후 치료까지 걸린 시간, 동반증상 유무, 기저 질환 유무, 초기 청력 저하 정도 등으로 알려져 있다.)

성인의 돌발성 난청과 달리 소아 돌발성 난청은 빈도가 적 고 예후가 불량한 것으로 여겨지며, 특히 10 세 이하에서는 10 세 초과의 소아에 비해 더욱 치료결과가 나쁘다는 보고가 있 다. ${ }^{910)}$ 성인 돌발성 난청에 대해서는 수많은 연구가 있어 왔지 만 소아 돌발성 난청의 임상양상 및 재발 등에 대한 연구는 체계적으로 이뤄지지 않은 실정이다. 이에 소아와 성인의 돌 발성 난청 양상을 비교해 보았고, 영상검사 결과 등을 비교해 재발 등 예후 및 치료 결정에 도움을 주고자 했다.

\section{대상 및 방법}

\section{대 상}

2005년 11월부터 2014년 5월까지 본원 이비인후과에서 돌 발성 난청 진단 하에 입원 치료를 받은 환자 중 15 세 이하인 소아 39명과 15세 이상 성인 226명을 대상으로 후향적으로 의무기록 분석을 시행하였다. 양측은 소아와 성인 각각 1 명이 어서 총 소아 40 귀와 성인 227 귀가 연구에 해당되었다. 돌발 성 난청 의심 환자 중 돌발성 난청 진단에 맞게 12 시간에서 3 일 정도 사이에 3 개 이상의 연속된 주파수에서 $30 \mathrm{~dB}$ 이상의 청력 감소를 겪은 환자 중 3 개월 이상 추적 관찰한 경우만 본 연구에 포함하였고, 1) 치료 시작 시기가 증상 발생 후 두 달 이 상 지난 경우, 2) 동반 질환 중뇌수막염, 척수염, 혈관염, 신경 정신과적 질환 또는 전정도수관 확장증(Enlarged vestibular aqueduct syndrome) 등 선천성 내이질환이 있는 경우, 3) 치 료 종료 3개월 후 추적 관찰 시 순음 청력 검사를 시행하지 않 은 경우를 본 연구에서 제외하였다. ${ }^{11)}$

환자의 연령 및 성별 분포, 초기 청력감소 정도, 치료결과, 영상 검사 결과 등을 분석하였으며, 발병 나이, 성별, 증상 발 생 후 치료시기, 동반증상 등의 요인에 따라 청력 회복률을 나누어 선출하였다.

\section{방 법}

소아 돌발성 난청의 치료는 성인 돌발성 난청과 마찬가지로 스테로이드 치료와 함께 저분자 덱스트란 제제 및 혈관확장제 (prostaglandin E1), ${ }^{11)}$ 혈류순환 개선제, Carbogen 흡입법을
시행하였다. ${ }^{12,13)}$

성인 돌발성 난청 환자의 경우 고용량의 전신 스테로이드 (methylprednisolone)를 1 4일째 $80 \mathrm{mg} / \mathrm{day}, 5 \sim 6$ 일째 60 $\mathrm{mg} / \mathrm{day}$, 7 8일째 $40 \mathrm{mg} / \mathrm{day}$, 9 10일째 $20 \mathrm{mg} / \mathrm{day}, 11 \sim 12$ 일째 $10 \mathrm{mg} / \mathrm{day}$ 로 줄여가며 근육 주사하였고, 소아의 경우 1 $\mathrm{mg} / \mathrm{kg} / \mathrm{day}$ 의 일정 용량으로 총 12 일간 입원 중 정맥 주사하 였다. ${ }^{14)}$

소아 환자 중 만 10세 이상의 9예에서 국소 마취 하에 고실 내 스테로이드 주입술을 시행하였다. ${ }^{15,16)}$

\section{청력검사 결과의 분석}

청력에 대한 평가를 위해 순음청력검사를 이용하여 청력 저하를 측정하였다. 입원 시, 입원 중, 퇴원 시, 추적관찰 1 개월 후, 3 개월 후로 나누어 순음청력검사를 시행하여 청력의 변화 를 관찰하였다. 초기 청력 소실의 정도는 경도 난청, 중등도 난 청, 중등고도 난청, 고등도 난청, 농으로 구분하였다. 청력의 최 종 회복 정도는 치료 시작 3 개월 후의 순음청력검사를 기준으 로 하였다.

청력회복의 판정은 Siegel ${ }^{17)}$ 의 분류를 따라 완전회복군, 부분회복군, 경도회복군, 불변군으로 분류하였다. 청력회복 의 기준은 경도회복군 이상으로 하여, 전체 회복률은 전체 환자 중 불변군을 제한 후 전체환자로 나누어서 구하였고 완 전 회복률은 완전 회복군을 전체환자로 나누어서 구하였다.

\section{통계학적 분석}

통계학적 분석은 SPSS version 22.0(SPSS Inc., Chicago, IL, USA)을 통해 Independent-sample t test와 chi-square test 및 Fisher's exact test를 사용하였고, $p$ 값이 0.05 미만인 경우를 통계학적으로 유의한 것으로 해석하였다.

\section{결 과}

\section{연령, 성별 및 측별 분포}

소아 돌발성 난청 환자의 나이는 만 3 세에서 15 세로 평균 연 령은 11세였으며 10세 이하는 20예(50\%)였다. 소아 돌발성 난 청 환자들 중 남자는 24예, 여자는 16예로 성비는 1:0.67이었 다. 좌우 분포는 우측이 23예, 좌측이 15예, 양측이 1예 해당 되었다. 내원 당시 청력소실 정도는 경도 난청이 4예(10\%), 중 등도 난청이 8예(20\%), 중등고도 난청이 8예(20\%), 고도 난 청이 5예(12.5\%), 농이 15예(37.5\%)였다. 성인 돌발성 난청 환 자는 남자는 100 명, 여자는 127 명이었고 좌우 분포는 우측이 114예, 좌측이 112예, 양측이 1예에 해당되었다. 내원 당시 청력 소실 정도는 경도 난청이 11예(4.8\%), 중등도 난청이 19예(8.4\%), 
중등고도 난청이 40예(17.6\%), 고도 난청이 59예(26\%), 농이 98 예(43.2\%)였다(Table 1).

\section{선행질환}

선행질환 중 바이러스 감염 확인을 위해 면역글로불린 $\mathrm{M}$, $\mathrm{G}$ (대상포진 바이러스, 거대세포 바이러스, 볼거리 바이러스, 엡스타인-바 바이러스, 풍진바이러스 등)를 검사한 경우가 16 예였고, 그중 2예에서 각각 거대세포 바이러스와 볼거리의 면역글로불린 M 양성을 확인하였다. 거대세포 바이러스 면역 글로불린 M 양성의 환자는 부분회복을 보였으며, 볼거리 면역 글로불린 $\mathrm{M}$ 양성의 환자는 불변군 소견을 보였다.

\section{전체적 회복률}

Siegel ${ }^{17)}$ 의 분류에 따르면, 소아 돌발성 난청 환자 40 예 중 완전회복이 12예(30\%), 부분회복이 5예(12.5\%), 경도회복이 7 예(17.5\%), 불변군이 16예(40\%)였으며 전체 회복률은 24예 (60\%)였다. 이는 성인 돌발성 난청 환자의 전체 회복률과 통계 적으로 유의한 차이가 없으나 완전 회복률에서는 통계학적으 로 유의하게 더 좋은 결과를 보였다 $\left(p_{\text {전체 }}>0.05, p_{\text {완전 }}<0.05\right)$ (Table 2).

\section{소아 환자 중 연령별 회복률}

소아 환자 40 예 중 10 세 이하는 20 예였고 완전회복 5 예

Table 1. Demographics of patients with sudden sensorineural hearing loss

\begin{tabular}{llc}
\hline & Child $(\mathrm{n}=40)$ & Adult $(\mathrm{n}=227)$ \\
\hline Age $($ mean \pm SD $)$ & $11 \pm 3.05$ & $50.4 \pm 15.5$ \\
Sex (male/female) & $24 / 16^{*}$ & $100 / 127^{*}$ \\
Side (right/left/both) & $23 / 15 / 1$ & $114 / 112 / 1$ \\
Initial hearing (dB) & & \\
Mild $(26-40)$ & $4(10 \%)$ & $11(4.8 \%)$ \\
Moderate $(41-55)$ & $8(20 \%)$ & $19(8.4 \%)$ \\
Moderate-severe $(56-70)$ & $8(20 \%)$ & $40(17.6 \%)$ \\
Severe $(71-90)$ & $5(12.5 \%)$ & $59(26.0 \%)$ \\
Profound $(\geq 91)$ & $15(37.5 \%)$ & $98(43.2 \%)$ \\
Average & $73.66^{\dagger}$ & $82.02^{\dagger}$ \\
\hline
\end{tabular}

*chi-square test, $p>0.05$, tindependent-sample t test, $p>0.05$

Table 2. Comparison of the recovery rate of child and adult

\begin{tabular}{lccc}
\hline & Child $(\mathrm{n}=40)$ & Adult $(\mathrm{n}=227)$ & $\mathrm{p}$ value* \\
\hline Complete recovery & $12(30 \%)$ & $32(13.5 \%)$ & 0.012 \\
Partial recovery & $5(12.5 \%)$ & $35(14.8 \%)$ & 0.093 \\
Slight improvement & $7(17.5 \%)$ & $70(29.5 \%)$ & 0.607 \\
No improvement & $16(40 \%)$ & $100(42.2 \%)$ & 0.227 \\
Overall recovery rate & $60 \%$ & $58 \%$ & 0.864 \\
\hline
\end{tabular}

Hearing recovery according to Siegel's criteria. *chi-square test
(12.5\%), 부분회복 3예(7.5\%), 경도회복 4예(10\%), 불변군 8예 (20\%)였으며 전체 회복률은 32예(80\%)였다. 11세 이상 15세 이하의 20예 중 완전회복 7예(17.5\%), 부분회복 2예(5\%), 경도 회복 3예(7.5\%), 불변군 8예(20\%)였으며 전체 회복률은 12예 (80\%)였다. 본 연구에서는 10 세 이하의 소아와 11 세 이상 소 아의 회복률이 통계적으로 유의한 차이가 없었다 $(p>0.05)$ (Table 3).

\section{소아 남녀별 회복률}

소아 환자 40예 중 남자는 24예였고 완전회복 6예(25\%), 부 분회복 3예(12.5\%), 경도회복 4예(16.7\%), 불변군 11예(45.8\%) 였으며 평균 치료 시작 시기는 8 일, 평균 초기 청력 정도는 79.68 $\mathrm{dB}$, 전체 회복률은 13 예(54.2\%)였다. 여자는 16예였고 완전회 복 6예(37.5\%), 부분회복 2예(12.5\%), 경도회복 3예(18.8\%), 불 변군 5예(31.2\%)였으며 평균 치료 시작 시기는 7일, 평균 초기 청력 정도는 $64.78 \mathrm{~dB}$, 전체 회복률은 11예(68.8\%)였다. 본 연 구에서는 남녀별 회복률의 차이가 없었다 $(p>0.05)$ (Table 4).

\section{동반증상에 따른 회복률}

어지럼증을 동반한 경우는 전체 40예 중 8예(20\%)였으며 동반되지 않은 경우는 나머지 32예(80\%)로 어지럼증을 동반 하지 않은 예가 많았으며, 초기 청력 저하 정도 및 치료 시작 시 기에서 차이가 없었다. 어지럼증을 동반한 경우의 회복률(62.5\%) 과 동반하지 않은 경우(59.4\%)가 차이가 없었다 $(p>0.05)$.

이명을 동반한 경우는 전체 40예 중 19예(47.5\%)였으며 동 반되지 않은 경우는 나머지 21예(52.5\%)로 이명을 동반한 예 가 더 많았으며, 초기 청력 저하 정도 및 치료 시작 시기에서 차이가 없었다. 이명을 동반한 경우의 회복률이(73.7\%) 동반 하지 않은 경우(26.3\%)와 차이가 없었다 $(p>0.05)$ (Table 5).

\section{치료 시작 시기에 따른 회복률}

소아 돌발성 난청 환자들은 발병한지 평균 7.6일 만에 내원 하여 치료를 시작하였다. 이는 성인의 5.3일보다 조금 늦은 것 으로 조사되었다. 증상 발생에서 치료 시작까지의 시기는 7일

Table 3. Recovery rate according to the age among children with sudden sensorineural hearing loss

\begin{tabular}{lccl}
\hline & $\begin{array}{c}\leq 10 \text { yrs } \\
(\mathrm{n}=20)\end{array}$ & $\begin{array}{c}11-15 \text { yrs } \\
(\mathrm{n}=20)\end{array}$ & p value \\
\hline Complete recovery & $5(12.5 \%)$ & $7(17.5 \%)$ & $0.731^{*}$ \\
Partial recovery & $3(7.5 \%)$ & $2(5 \%)$ & $1.00^{*}$ \\
Slight improvement & $4(10 \%)$ & $3(7.5 \%)$ & $1.00^{*}$ \\
No improvement & $8(20 \%)$ & $8(20 \%)$ & $1.00^{\dagger}$ \\
Overall recovery rate & $80 \%$ & $80 \%$ & $1.00^{+}$ \\
\hline
\end{tabular}

Hearing recovery according to Siegel's criteria. *Fisher's exact test, ${ }^{+}$chi-square test 
Sudden Sensorineural Hearing Loss in Child I Shin DJ, et al.

Table 4. Comparison of the hearing recovery between maleand female among children

\begin{tabular}{lccc}
\hline & Male $(\mathrm{n}=24)$ & Female $(\mathrm{n}=16)$ & $\mathrm{p}$ value \\
\hline Complete recovery & $6(25 \%)$ & $6(37.5 \%)$ & $0.490^{\dagger}$ \\
Partial recovery & $3(12.5 \%)$ & $2(12.5 \%)$ & $1.00^{\dagger}$ \\
Slight improvement & $4(16.7 \%)$ & $3(18.8 \%)$ & $1.00^{\dagger}$ \\
No improvement & $11(45.8 \%)$ & $5(31.2 \%)$ & $0.512^{*}$ \\
Overall recovery rate & $13(54.2 \%)$ & $11(68.8 \%)$ & $0.512^{\dagger}$ \\
Average initial treatment onset time (days) & 8 & 7 & $0.798^{\ddagger}$ \\
Initial hearing (dB) & 79.58 & 64.78 & $0.058^{\ddagger}$ \\
\hline
\end{tabular}

Hearing recovery according to Siegel's criteria. *Fisher's exact test, ${ }^{\dagger}$ chi-square test, $\neq$ Independent-sample $\dagger$ test

Table 5. Recovery rate according to accompanied symptom

\begin{tabular}{lcccc}
\hline & With dizziness $(\mathrm{n}=8)$ & Without dizziness $(\mathrm{n}=32)$ & With tinnitus $(\mathrm{n}=19)$ & Without tinnitus $(\mathrm{n}=21)$ \\
\hline Complete recovery & $2(25 \%)$ & $10(31.3 \%)$ & $7(36.8 \%)$ & $5(23.8 \%)$ \\
Partial recovery & $1(12.5 \%)$ & $4(12.5 \%)$ & $2(10.5 \%)$ & $3(14.3 \%)$ \\
Slight improvement & $2(25 \%)$ & $5(15.6 \%)$ & $5(26.3 \%)$ & $2(9.5 \%)$ \\
No improvement & $3(37.5 \%)$ & $13(40.6 \%)$ & $5(26.3 \%)$ & $11(52.4 \%)$ \\
Overall recovery rate & $63 \%$ & $59.4 \%$ & $73.7 \%$ & $47.6 \%$ \\
Average Initial treatment & 4.75 & 8.34 & 9.42 & 6 \\
$\quad$ onset time (days) & & & 70.2 & 76.8 \\
Initial hearing (dB) & 79.69 & 72.16 & & \\
\hline
\end{tabular}

Hearing recovery according to Siegel's criteria. *Fisher's exact test, $p>0.05$, †ndependent-sample $\dagger$ test, $p>0.05$

Table 6. Recovery rate according to initial treatment onset time

\begin{tabular}{lccc}
\hline & Within 7 days $(\mathrm{n}=28)$ & After 7 days $(\mathrm{n}=11)$ & $\mathrm{p}$ value \\
\hline Complete recovery & $11(39.3 \%)$ & $1(8.3 \%)$ & $0.067^{*}$ \\
Partial recovery & $2(7.1 \%)$ & $3(25 \%)$ & $0.149^{*}$ \\
Slight improvement & $4(14.3 \%)$ & $3(25 \%)$ & $0.410^{*}$ \\
No improvement & $11(39.3 \%)$ & $5(41.7 \%)$ & $1.00^{*}$ \\
Overall recovery rate & $17(59.3 \%)$ & $7(58.3 \%)$ & $0.145^{\dagger}$ \\
\hline
\end{tabular}

Hearing recovery according to Siegel's criteria. $*$ Fisher's exact test, ${ }^{\dagger}$ chi-square test

이내의 경우가 28 예로 가장 많았으며 7 일 이후인 경우는 12 예였고 이 중 28 일 이상은 3예였다. 7일 이내에 치료를 시작한 경우는 완전 회복 11예(39.3\%), 부분회복 2예(7.1\%), 경도회복 4예(14.3\%), 불변군 11예(39.3\%)였으며 전체 회복률은 17예 (59.3\%)였다. 7일 이후에 치료가 시작된 경우는 완전 회복 1예 (8.3\%), 부분회복 3예(25\%), 경도회복 3예(25\%), 불변군 5예 (41.7\%)였으며 전체 회복률은 7예(58.3\%)였다. 치료 시작 시기 에 따른 전체 회복률은 차이가 없었고, 완전 회복률은 7일 이내 치료를 시작한 경우가 7일 이후 치료를 시작한 경우보다 수치적으로는 더 높았으나 통계적으로는 유의하지 않았다 $(p>0.05)$ (Table 6).

\section{재발률}

소아 돌발성 난청 환자에서 재발은 3예(7.5\%)에서 보였다. 2예에서는 완전히 이전 청력으로 회복되었던 환아였다. 성인 에서는 5 예 $(2 \%)$ 에서 재발 소견을 보여 성인과 소아에서 재발
률에 유의한 차이가 없었다 $(p>0.05)$. 재발된 소아의 경우 2예 는 1 개월 후 다시 발병하였고, 1 예는 3 년 후 발병하였다.

\section{기질적 이상의 유무}

기질적 이상을 확인하기 위해 소아 돌발성 난청 환자 중 총 36 예에서 영상검사를 시행하였고, 그중 28예에서 측두골 자기 공명촬영(temporal MRI)을, 21예에서 측두골 전산화단층촬 영(temporal CT)을 촬영하여 내이, 청신경의 이상 소견 여부를 체크하였다. 영상 검사를 시행한 환자 중 5 예에서 염증 소견 을 제외한 이상소견[Mega cisternal magna, arachnoid cyst, Asymmetric internal auditory canal(IAC) diameter, Focal moderate stenosis at right internal carotid artery(ICA), Hydrocephalus 등]을 보였다. 최종 청력 평가 시 부분회복 1 예 (20\%), 경도회복 1예(20\%), 불변군 3예(60\%)였으며 전체 회 복률은 2예(40\%)에 해당하였다.

성인 돌발성 난청환자는 영상검사를 시행한 총 147 예 중 35 
예(23\%)에서 급성반응 혹은 염증을 제외한 만성적 이상소견 [Rathke's cleft cyst in the sella, aneurysm at right middle cerebral artery(MCA), stenosis at left MCA, well-defined nonenhancing cystic lesion in sella area 등]을 보였다. 최종 청력 평가 시 완전회복 1예(2.9\%), 부분회복 6예(17.1\%), 경도회복 12 예(34.3\%), 불변군 16예(45.7\%)였다.

소아 재발 환자 4예 모두 영상 검사를 시행하였으며 성인 재 발 환자 5예 중 4예에서 MRI를 시행하였고, 이들 중이, 내이 및 청신경 이상소견은 보이지 않았다.

\section{고 찰}

돌발성 난청은 수 시간에서 수일 내 갑자기 발생하는 설명 되지 않은 이명 및 어지럼증을 동반되는 감각신경성 난청이 다. 그동안 많은 연구들에서 원인 및 치료와 발생기전에 대해 조사하였으나 정확한 발생기전 등은 확립되지 않았다. 돌발 성 난청은 이과적 응급질환으로 영구적 후유증을 남길 수 있기 때문에 빠른 시기에 진단 및 치료를 시작하는 것이 중요 하다. ${ }^{2)}$

기존의 연구들을 통해 일반적으로 돌발성 난청은 남성과 여성 및 좌측 귀와 우측 귀에서 동일한 비율로 발생한다고 알 려져 있다.1,18) 본 연구에서 성인 돌발성 난청 환자는 남녀 및 좌우분포가 그 전 연구처럼 유사한 것으로 보이나, 소아의 경우 남녀별 유병률 차이가 없었으며, 좌우의 차이가 없었다 $(p>0.05)$. 양측 돌발성 난청의 경우 돌발성 난청 환자의 $4 \sim 17 \%$ 에서 양측으로 발생한다고 알려져 있으며, 본 연구에서 소아 1 예, 성인 1예가 보였다.

돌발성 난청의 선행질환 확인을 위해 바이러스 감염(대상 포진 바이러스, 거대세포 바이러스, 볼거리 바이러스, 엡스타 인-바 바이러스, 풍진바이러스 등에 대한 titer 등) 검사한 경 우가 16예였고, 그중 2예에서 각각 거대세포 바이러스와 볼거 리의 면역글로불린 $\mathrm{M}$ 양성을 확인하였다. 각각의 예에서 환 자들은 부분회복 및 불변군 소견을 보였으나 단 2예에 불가 하여 통계학적 의의를 갖기는 어려워 보인다.

기존의 연구들에서 제시한 돌발성 난청 환자의 예후 예측 인자로는 치료 시작 시기, 어지럼증 및 이명의 동반 여부, 환자 의 연령 등이 있다. ${ }^{19,20)}$

소아 돌발성 난청은 성인 돌발성 난청에 비해 빈도는 적지 만 예후가 불량한 것으로 여겨졌다. Chon 등은 은 10 세 이하 소아에서는 치료결과가 10 세 이상의 소아보다 나쁘다고 보고 하였는데, 그 이유로는 소아의 경우 증상 호소가 명확하지 않 아 감별이 불분명하고 그로 인해 조기 치료의 빈도가 낮은 것 이 원인이라고 하였다.
이에 반해 Moon 등릐 의 연구와 본 연구에서는 소아 돌발성 난청이 성인에 비해 전체적인 회복률에서 차이를 보이지 않았 으며, 10 세 이하의 유·소아와 11 세 이상 소아의 회복률에 유 의한 차이가 없었다.

소아 환자 중 남성과 여성의 유병률 및 회복률과 초기 청력 정도, 치료 시작 시기의 차이는 없었다. 성인 돌발성 난청의 경 우, 어지럼증 및 이명을 동반하는 것이 예후에 영향을 주는 지에 대해 의견이 다양한데, ${ }^{9021-23)}$ 본 연구에서 소아의 경우 어지럼증이나 이명을 동반하는 경우와 동반하지 않는 경우 에서 차이가 없었다.

Moon 등 21) 기존의 연구들에서는 돌발성 난청의 치료시기 가 빠른 환자의 전체 회복률이 더 높다고 하였다.8,20,21,24,25)

결론적으로 소아 돌발성 난청은 남녀별, 측별 발생률에 차 이가 없었고, 성인의 경우와 유사한 전체 회복률을 보였다. 다만, 완전 회복률에서는 성인보다 더 좋은 결과를 보였다. 어지럼증이나 이명을 같은 동반증상의 유무나 치료 시작시키 는 회복률에 영향이 없었다. 재발률은 성인과 소아에서 차이 가 없고, ${ }^{26)}$ 기질적 이상소견을 보이는 경우가 있어 영상 검사를 시행해야 한다.

\section{REFERENCES}

1) Nakashima T, Itoh A, Misawa H, Ohno Y. Clinicoepidemiologic features of sudden deafness diagnosed and treated at university hospitals in Japan. Otolaryngol Head Neck Surg 2000;123(5):593-7.

2) Rambold H, Boenki J, Stritzke G, Wisst F, Neppert B, Helmchen C. Differential vestibular dysfunction in sudden unilateral hearing loss. Neurology 2005;64(1):148-51.

3) Na SY, Kim MG, Hong SM, Chung JH, Kang HM, Yeo SG. Comparison of sudden deafness in adults and children. Clin Exp Otorhinolaryngol 2014;7(3):165-9.

4) Fetterman BL, Saunders JE, Luxford WM. Prognosis and treatment of sudden sensorineural hearing loss. Am J Otol 1996;17(4):529-36.

5) Kosugi EM, Tangerina RP, Dib GC, Ramos HVL, Penido NO. Vestibular schwannoma presenting as sudden hearing loss. Rev Bras Otorrinolaringol 2004;70(6):795-9.

6) Tucci DL, Farmer JC Jr, Kitch RD, Witsell DL. Treatment of sudden sensorineural hearing loss with systemic steroids and valacyclovir. Otol Neurotol 2002;23(3):301-8.

7) Park KH, Lee CK, Lee JD, Park MK, Lee BD. Combination therapy with systemic steroids, an antiviral agent, anticoagulants, and stellate ganglion block for treatment of sudden sensorineural hearing loss. Korean J Audiol 2012;16(2):71-4.

8) Uysal İÖ, Müderris T, Polat K, Yüce S, Gültürk S. Is the time from the onset to the treatment a prognostic indicator for hearing recovery in idiopathic sudden sensorineural hearing loss? Kulak Burun Bogaz Ihtis Derg 2015;25(2):70-6.

9) Chon KM, Goh EK, Lee IW, Cho KS. Clinical observation of sudden deafness in children. Korean J Otolaryngol-Head Neck Surg 2002; 45(5):456-61.

10) Ahn JH, Yoon TH, Chung JW. Analysis of prognosis in patients with sudden sensorineural hearing loss and dizziness. Korean J Otolaryngol-Head Neck Surg 2001;44(10):1032-7.

11) Lee HY, Kim JC, Chang DS, Choi MS, Cho CS, Kim AY. Therapeutic effect of Zinc and lipoprostaglandin E1 for idiopathic sudden hearing 
loss. Korean J Otorhinolaryngol-Head Neck Surg 2015;58(5):318-23.

12) Lee HJ, Park CY, Lee JH, Yang HS, Kim JH, Ban MJ, et al. Therapeutic effects of carbogen inhalation and lipo-prostaglandin el in sudden hearing loss. Yonsei Med J 2012;53(5):999-1004.

13) Suzuki H, Fujimura T, Ikeda K, Shiomori T, Udaka T, Ohbuchi $T$, et al. Prostaglandin E1 in combination with hyperbaric oxygen therapy for idiopathic sudden sensorineural hearing loss. Acta Otolaryngol 2008;128(1):61-5.

14) Nakache G, Migirov L, Trommer S, Drendel M, Wolf M, Henkin Y. Steroid-based treatments for patients with total sudden sensorineural hearing loss. Acta Otolaryngol 2015;135(9):907-13.

15) Günel C, Başal Y, Toka A, Eryılmaz A, Kurt Ömürlü I. Efficacy of low-dose intratympanic dexamethasone for sudden hearing loss. Auris Nasus Larynx 2015;42(4):284-7.

16) Tsai HT, Hsueh $N$, Huang CM, Lin HC. Intratympanic steroid injection as a first-line therapy in uremia patients with sudden sensorineural hearing loss. Acta Otolaryngol 2015;135(8):786-90.

17) Siegel LG. The treatment of idiopathic sudden sensorineural hearing loss. Otolaryngol Clin North Am 1975;8(2):467-73.

18) Shin SO. Clinical characteristics and management of sudden sensorineural hearing loss. Korean J Audiol 2011;15(1):1-7.

19) Zadeh MH, Storper IS, Spitzer JB. Diagnosis and treatment of suddenonset sensorineural hearing loss: a study of 51 patients. Otolaryngol
Head Neck Surg 2003;128(1):92-8.

20) Park SN, Yeo SW, Park KH, Park SY, Cheun BC, Song CE, et al. The characteristics and the changes of tinnitus according to the recovery of hearing loss in the patients with sudden hearing loss. Korean J Otolaryngol-Head Neck Surg 2004;47(3):222-6.

21) Moon YE, Yang SD, Choi JC, Kim MS, Oh JK, Kim HA. Clinical characteristics and treatment results of sudden deafness in children. Korean J Otorhinolaryngol-Head Neck Surg 2009;52:805-9.

22) Cho CS, Choi YJ. Prognostic factors in sudden sensorineural hearing loss: a retrospective study using interaction effects. Braz J Otorhinolaryngol 2013;79(4):466-70.

23) Hong BS, Chung WH, Park KH, Jung YG, Hong SW, Choo KC. Whirling vertigo as a prognostic factor in sudden sensorineural hearing loss. Korean J Otolaryngol-Head Neck Surg 2002;45:651-5.

24) Tiong TS. Prognostic indicators of management of sudden sensorineural hearing loss in an Asian hospital. Singapore Med J 2007;48(1):45-9.

25) Tarshish Y, Leschinski A, Kenna M. Pediatric sudden sensorineural hearing loss: diagnosed causes and response to intervention. Int J Pediatr Otorhinolaryngol 2013;77(4):553-9.

26) Park IS, Kim YB, Choi SH, Hong SM. Clinical analysis of recurrent sudden sensorineural hearing loss. ORL J Otorhinolaryngol Relat Spec 2013;75(4):245-9. 